land. Ownership of the land is not affected and the normal life and work of the area continue.

\section{The Future of Education in Britain}

In his presidential address to the National Union of Teachers delivered on April 20, Mr. J. Archbold, referring to the increasing demand for more scientists, technologists and technicians, said that this demand can only be met by the co-operative effort of all teachers. Sound foundations are essential, but he believes we are falling behind the United States, the U.S.S.R. and other industrial powers in the training of scientists and technologists. He urged that a tenyear plan is required to implement most, if not all, of the reforms promised in the Education Act of 1944, and in the order of priorities he put first the reduction in the size of classes to at least the maximum figures quoted in the Ministry of Education regulations. His second priority was to implement the National Advisory Council's report upon a threeyear teacher training course, and to introduce the extended period of training by 1960 . Next, he put the increase in the number of scientists, technologists and technicians, and in this connexion he said that greater efforts are required throughout the educational system of Britain at school age to provide a liberal education. Extended facilities for universities and technical colleges are also required, as well as adequate maintenance grants, taxation reliefs and family allowances; a choice will have to be made between raising the school-leaving age to sixteen and providing county colleges and part-time education to eighteen. Mr. Archbold favours the latter in present circumstances. He also emphasized the part played by the home, the employer and the State in education and, while welcoming the stand taken both by Sir David Eecles and Lord Hailsham for the development of education, expressed concern that the Government's recent decision in regard to block grants would lead to reduced expenditure on education.

\section{Radio Astronomy}

The January 1957 number of the American Scientist is a commemorative issue to mark the seventieth anniversary of the founding of the Society of the Sigma Xi. Two of the main articles are devoted to the subject of radio astronomy. The first, "The Beginnings of Radio Astronomy", by C. M. Jansky, jun., which was presented to a meeting of the American Astronomical Society on March 26, 1956, is an appreciation of his late brother's (Karl Guthe Jansky) discovery of, and contribution to, radio astronomy. As he aptly puts it, "Karl Jansky gave us our first brief look at interstellar space through a new and previously unknown window in the electromagnetic spectrum". The second, "The Develop. ment of Radio Astronomy", by G. S. Hawkins (Harvard College Observatory), gives a detailed description of the equipment used by radio astronomers and the results obtained recently, including signals from the Sun, radio stars, the Milky Way and Jupiter. Radar astronomy is briefly described, but it is emphasized that it will probably never become as spectacular as radio astronomy. Other articles in the issue are "A Survey of the Particles of Physics", by A. H. Snell (Oak Ridge), which gives a general picture of the various elementary particles, including the antiproton and antineutron, and their properties known at the end of 1956, and "Automation", by W. J. Cunningham, which is a non-technical but clear description of feedback or automatic control and the various fields in which it may be applied.

\section{A Question of Gravity}

DR. B. W. Hirsh, of Harrogate, has raised the question of whether it is possible for a liquid and its vapour to co-exist in equilibrium under such compression that the vapour is denser than the liquid. Miss K. M. Gratwick writes: Such conditions have been obtained with certain binary systems under high pressure. The phenomenon was first observed by Kamerlingh Onnes with a helium-hydrogen mixture (Proc. Koninkl. Ned. Akad. Wet., 9, 459; 1906). At liquid hydrogen temperatures and at pressures less than 49 atmospheres, the phase richer in helium is the lighter, whereas at greater pressures it is the heavier. The effect is reversible and by varying the pressure a 'gas' bubble could be made to rise or sink at will through the liquid.

Lindroos and Dodge (Chem. Eng. Progress, Symp. Ser. $3,48,10$; 1952) have observed a similar phenomenon with nitrogen-ammonia mixtures throughout the range of temperatures $\left(30^{\circ}-110^{\circ} \mathrm{C}\right.$.) investigated. At pressures less than 1,820 atmospheres, the ammonia-rich phases are the denser, but above 2,100 atmospheres they are lighter. Such barotropic effects arise in systems containing two components, due to changes in their relative compressibilities under conditions in which the densities of the liquid and vapour phases are nearly equal, that is, in the critical region of the mixture.

Anomalies of the European Aerological Network

IT has been recognized for the past century that international intercomparability of meteorological observations is essential. The World Meteorological Organization has been developed with that object as one of the leading purposes of its existence. It must, however, regretfully be realized that such intercomparability does not exist over Europe for one of the latest kinds of observation, the measurement of pressure and temperature in the upper air by radiosonde. Nine types of radio-sonde are in use in Europa, and the differences between them are serious, as is well brought out in a pamphlet by the director of the Swiss Meteorological Office and the chief of the Swiss Aerological Observatory (J. Lugeon and P. Ackermann. Les anomalies du réseau aérologique européen. Tirage à part des "Annales de la Station centrale suisse de Météorologie", 1955. Zurich, 1956). The differences are due to variations in susceptibility of the temperature elements to solar radiation, in lag, in thermal coefficient of the pressure-measuring unit, and instability after calibration. Unfortunately these are not direct zero errors but vary with height, day, night and season. They can be serious because upper winds are forecast from the charts of radiosonde observations, and the contour lines of isobaric surfaces shown on the charts are, it is recognized, sometimes falsified by these differences. The analysis in the paper is made by plotting values and drawing sections across Europe of mean values of the layer thicknesses between fixed pressures for duy and night, summer and winter. Charts are also drawn for standard deviations of the same quantities. The cross-sections show discontinuities, and the charts tortuous isopleths, which cannot be attributed to orographic effects and are clearly due to the different types of radiosonde. Differences of the order of 1.5 per cent of the true height exist. The design of radiosondes, instruments in which the desirable qualities 